\title{
Colorectal cancer screening and prevention-pros and cons
}

\author{
Markus Niederreiter · Lukas Niederreiter · Andreas Schmiderer · Herbert Tilg • Angela Djanani
}

Received: 7 May 2019 / Accepted: 13 August 2019 / Published online: 13 September 2019

(C) The Author(s) 2019

\begin{abstract}
Summary Colorectal cancer (CRC) is one of the most frequent cancer entities worldwide and a leading cause of death. The disease is known to develop from potentially curable, premalignant lesions over several years and therefore is suitable for screening procedures and preventive measures. Several trials have demonstrated reduced incidence and mortality in screening cohorts. A multitude of different screening strategies for CRC have been implemented in different parts of the world. While randomized controlled studies directly comparing screening procedures are still ongoing, colonoscopy remains the gold standard for screening and the only procedure that allows to effectively prevent CRC by treating premalignant lesions. However, population-wide participation rates vary greatly but often only reach approximately $25 \%$. Noninvasive screening strategies are indispensable to increase acceptance rates and for resource-limited regions with limited capacity for colonoscopy. Importantly, while incidence of CRC increases with age, lately we have seen a raise in incidence for CRC in the population below 50 years of age, potentially requiring to include younger adults (e.g., 45 years of age) into established screening programs. It remains important to continue to gather data and evidence regarding effectiveness of various screening strategies, preferably in randomized controlled trials. This short review will outline currently established screening procedures and will discuss the pros and cons for each individual approach.
\end{abstract}

\footnotetext{
M. Niederreiter $\cdot$ L. Niederreiter · A. Schmiderer · H. Tilg •

A. Djanani $(\bowtie)$

Department of Internal Medicine I, Division of Gastroenterology, Hepatology, Metabolism and Endocrinology, University Hospital Innsbruck, Anichstraße 35, 6020 Innsbruck, Austria angela.djanani@i-med.ac.at
}

Keywords FIT · Colonscopy · gFOBT · Screening · Surveillance

\section{Take Home Message}

Screening for colorectal cancer has immense potential for reducing mortality and cost from this deadly disease. It should be of top priority for health care providers in each country to include as many people as possible in established screening programs.

\section{Introduction}

Despite prophylactic lifestyle strategies and globally established screening programs, colorectal cancer (CRC) remains one of the most prevalent cancer entities especially in developed countries with 1.8 million new cases and 861,000 deaths in 2018 according to World Health Organization (WHO) Globocan Database.

Incidence of disease increases sharply with age, especially above age 50. However, more recent data show that previously low-risk populations below age of 50 exhibit an increase in incidence while a slow decrease in incidence above 50 years of age, presumably due to effective screening procedures, has been noted [1].

The development of the disease is known to progress over several years from precursor lesions, which are potentially curable, to fully developed CRC [2]. Therefore, detecting and treating these early lesions has become the objective of established screening programs worldwide resulting in a significant decrease in mortality [3-5].

New chemotherapeutic regimes have mildly improved the survival of metastatic disease while raising the costs for health care providers immensely. There- 
fore, screening has not only decreased the mortality of CRC but might also be highly cost-effective [6].

The aim of this short review is to give an overview of the advantages and disadvantages of currently used screening procedures and tests.

\section{Prophylaxis}

Preventing CRC stands on two pillars: prophylaxis by eliminating risk factors and cultivating a healthy lifestyle and effective screening programs.

Drinking alcohol and smoking have been shown to increase CRC incidence and mortality [7, 8], and motivating the patient to eliminate those habits should therefore be a priority for healthcare providers. Furthermore, obesity and diet have been shown to have an impact on CRC incidence [9]. Reducing weight and red meat intake decreases the risk of developing CRC [10]; however, further recommendations on diet are less clear and partly conflicting. While some studies suggest a protective role of a diet rich in vegetables and fruits other studies have challenged this assumption $[11,12]$. While more studies are required, it is recommended to closely follow the World Cancer Research Fund/American Institute for Cancer Research cancer prevention guidelines and recommendations [13]. The data is clearer for physical activity showing a reduction of CRC risk with regular physical activity in a meta-analysis of 21 studies [14].

Aspirin use has been shown to reduce the incidence of adenomatous polyps; however, due to its frequent side effects like gastrointestinal bleeding the intake as a prophylactic agent is not recommended [15].

\section{Screening methods}

\section{Guaiac fecal occult blood test and fecal immunochemical testing}

Guaiac fecal occult blood test (gFOBT) screening has long been shown to reduce mortality from CRC. A Cochrane review revealed a decrease in relative mortality risk of CRC of $16-25 \%$ [16]. The test is inexpensive and therefore suitable for a large population. However, it lacks sensitivity for CRC and advanced adenomas which is partly compensated by more frequent testing [17], thus decreasing patient acceptance and compliance.

Fecal immunochemical testing (FIT) showed an improved sensitivity and specificity when compared to gFOBT especially for advanced adenomas, albeit at a higher cost [18]. Further advantages include the requirement of a single stool sample and that it does not require dietary restrictions prior to testing. A study from Italy demonstrated a $22 \%$ mortality reduction from CRC in regions introducing FIT-based screening [19]. One point of ongoing discussion are varying cutoff levels between different FIT test kits resulting in different specificity and sensitivity between test kits
[20]. Higher cutoff levels result in higher specificity and positive predictive value and vice versa lower cutoff levels increase sensitivity for advanced neoplasias [21]. A key advantage of FIT-based screening is the higher acceptance rate compared to colonoscopy; however, it lacks sensitivity for premalignant lesions making it less suitable for prevention of CRC [22].

\section{Multitarget stool DNA testing}

Stool DNA testing is performed by a conglomerate of molecular assays for several targets namely aberrant BMP3, NDRG4 methylation of promoter regions and mutant KRAS and B-actin combined with an immunochemical assay as used in FIT test kits. The test is performed with a single stool sample and showed significantly increased sensitivity of 20 percentage points when compared to FIT, though with less specificity [23].

Frequency of testing is not well established; however, due to high sensitivity it may be extended to once every 3 years, which could aid to increase participation rates.

However, its role in large screening programs is still part of discussion as the decreased specificity leads to more false-positive results, therefore raising the number of needed follow-up colonoscopies. Moreover, due to higher cost compared to FIT, even at a 3-year test interval, FIT is still recommended as the first-line noninvasive screening test [24].

\section{Colonoscopy and flexible sigmoidoscopy}

Colonoscopy is considered the gold standard for colon cancer screening with higher sensitivity and specificity than FOBT for detecting adenomas and CRC [22]. Furthermore, colonoscopy and sigmoidoscopy are the only established screening measures that also allow to prevent cancer by effectively removing precursor lesions [25]. Several trials have demonstrated a decrease in CRC incidence and mortality in colonoscopy screening cohorts $[3,5]$. While randomized controlled trials using colonoscopy as a screening procedure are still ongoing, randomized controlled studies showing a reduction in CRC mortality have been published for the use of flexible sigmoidoscopy [26, 27]. Complication rates of endoscopy are generally low; however, the bowel preparation is cumbersome with low acceptance rates by patients. Moreover, the procedure depends on high quality standards, such as adenoma detection rate (ADR), cecum intubation and postcolonoscopy cancer rate and therefore needs to be performed by well-trained endoscopists.

Depending on availability, colonoscopy is either the first-line screening method or performed subsequently to a prior positive noninvasive test such as FIT. 


\section{MR colonography and CT colonography}

Most recent metanalysis comparing colonoscopy to CT colonography (CTC) revealed a high sensitivity of a $100 \%$ for cancer detection and $87.9 \%$ for adenomas $\geq 10 \mathrm{~mm}$ and a lower sensitivity for smaller adenomas [28, 29]. However, CTC exposes patients to radiation with subsequent increased risk to develop neoplasias. Moreover, CTC fails to remove precancerous lesions which renders CTC only a valid choice for patients who cannot undergo colonoscopy for technical reasons.

Data for MR colonography is very limited and therefore it is currently not recommended as a screening procedure.

\section{Novel developments-liquid biopsy}

Tumors shed different biomarkers including DNA, RNA, miRNA and proteins into the blood. Obtaining circulating tumor DNA may indicate relapse after surgical resection of CRC. However, liquid biopsy is limited when it comes to early detection of CRC or adenomas because of minimal amounts of ctDNA shed by early stages. Deviant methylation detection of free circulating DNA on the Septin 9 gene promoter is another approach used by the recently improved EpiproColon 2.0 assay, which demonstrated a sensitivity of up to $84 \%$ in a small cohort of stage I CRC. Similar markers have shown a comparable sensitivity and combining multiple biomarkers seems to improve the ability to detect CRC [30]. miRNA alterations which drive cells into an undifferentiated proliferative state have been shown to play a role in a variety of tumor entities including CRC. The most researched indicative marker is miR-21 with a pooled sensitivity and specificity of 72 and $85 \%$, respectively. Combining multiple miRNA biomarkers on panel tests showed an improved sensitivity of about $81 \%$ and specificity of $84 \%$ [30].

Utilizing these techniques for screening is a promising new approach; however, currently no established markers used for screening are available and further prospective evaluation studies are needed for clinical use.

\section{Screening population}

Recent epidemiologic data showing an increase in CRC incidence among young adults below 50 years of age and a concomitant decline in the screening cohorts aged 50 and above have raised the question whether to lower the starting age of screening programs to 45 instead of age 50 [31]. The American Cancer Society has already issued the recommendation to lower the starting age for all average-risk individuals to 45 [32]. Imperiale et al. highlight the potential benefit of this new approach, possibly detecting curable stage CRC in this age group, while also lowering the cost of cancer treatment. This has to be balanced by more unnecessary screening procedures and potential complications when lowering screening age even further alongside increased cost due to increased screening [31]. Therefore, it seems that screening colonoscopy from age 45 to 75 years every 10 years was most favorable [31]. However, the US Multi-Society Task Force on Colorectal Cancer, among others, still recommend to start screening at age 50 for individuals at average risk [24].

Some countries have started to use noninvasive stool tests with subsequent colonoscopy if the test turned out positive starting at age 45 . Whether there should be a general recommendation for lowering the starting age for screening by colonoscopy for all average risk individuals requires further evidence.

\section{Discussion}

It has been clearly demonstrated that screening for CRC and the removal of precancerous lesions by colonoscopy results in a reduction of incidence and mortality, while also being cost-effective for the healthcare system. Endoscopy is widely considered as a gold standard and is the only screening procedure that also allows to remove precancerous adenomas. However, studies comparing screening strategies that combine different available screening procedures at given intervals may yield comparative results with higher acceptance rates for noninvasive procedures. In a simulation study by the US preventive service task force, colonoscopy every 10 years, annual FIT, sigmoidoscopy every 10 years with annual FIT and CTC every 5 years yielded comparable amounts of life years gained when performed in a screening population from 50 years of age 75 years of age [33]. A current comparative evaluation of FIT and colonoscopy for screening revealed a much higher participation rate in the FIT group and similar detection rates of $\mathrm{CRC}$ in both groups. More adenomas were however identified and treated in the colonoscopy group [22]. Potential complications of an invasive procedure such as colonoscopy, high cost and the reliance on high quality standards need to be taken into account. As no randomized controlled comparative studies are currently available screening procedures may vary by country also depending on resources within the healthcare system and patient acceptance. Noninvasive stool tests provide a good alternative for patients refusing colonoscopy or in countries with limited access to colonoscopy. Table 1 summarizes the currently internationally most established screening procedures and tests, and their level of recommendation based on the systematic review of evidence of the US MultiSociety Task Force on Colorectal Cancer [24]. Ultimately, the goal of screening programs should be to multiply participation rates and patient adherence. Newer developments such as liquid biopsy testing for biomarkers such as ctDNA and miRNA could further 
Table 1 Commonly recommended colorectal (CRC) screening procedures

\begin{tabular}{|c|c|c|c|c|c|}
\hline $\begin{array}{l}\text { Screening } \\
\text { procedure }\end{array}$ & $\begin{array}{l}\text { Level of } \\
\text { recommen- } \\
\text { dation }^{\mathrm{a}}\end{array}$ & $\begin{array}{l}\text { Recommended } \\
\text { frequency of } \\
\text { testing }\end{array}$ & Sensitivity and specificity & Pros & Cons \\
\hline Colonoscopy & Tier 1 & Every 10 years & $\begin{array}{l}\text { Adenomas } \geq 6 \mathrm{~mm} \text { : sensitivity: } \\
75 \text { to } 93 \% \text {, specificity: } 94 \% \\
\text { Adenomas } \geq 1 \mathrm{~cm} \text { : sensitivity: } \\
89 \text { to } 98 \% \text {, specificity: } 89 \% \\
\text { [32] }\end{array}$ & $\begin{array}{l}\text { Prevention by treating premalig- } \\
\text { nant lesions } \\
\text { High sensitivity for CRC and } \\
\text { precancerous lesions } \\
\text { Long screening intervals if } \\
\text { negative }\end{array}$ & $\begin{array}{l}\text { Tedious bowel preparation } \\
\text { High quality standards needed/ } \\
\text { operator dependent } \\
\text { Low, but possible risk of ad- } \\
\text { verse events (bleeding, perfora- } \\
\text { tion, aspiration, splenic injury) }\end{array}$ \\
\hline FIT & Tier 1 & Annually & $\begin{array}{l}\text { CRC: } 74 \% \text { sensitivity, } 96 \% \\
\text { specificity [23] } \\
\text { advanced adenomas: } 24 \% \\
\text { sensitivity, } 94 \% \text { specificity [23] }\end{array}$ & $\begin{array}{l}\text { Noninvasive } \\
\text { Relatively low cost } \\
\text { Reasonably high one time sensi- } \\
\text { tivity for CRC }\end{array}$ & $\begin{array}{l}\text { Frequency of testing } \\
\text { Colonoscopy needed if positive } \\
\text { Low sensitivity for precancerous } \\
\text { lesions }\end{array}$ \\
\hline $\begin{array}{l}\text { Multitargeted } \\
\text { stool DNA test }\end{array}$ & Tier 2 & Every 3 years & $\begin{array}{l}\text { CRC: } 1 \text {-time sensitivity of } 92 \% \\
\text { [23] } \\
\text { Serrated Class precursor le- } \\
\text { sions: } 40 \% \text { sensitivity [23] } \\
\text { Specificity: } 86 \%[23]\end{array}$ & $\begin{array}{l}\text { Noninvasive } \\
\text { High 1-time sensitivity for CRC } \\
\text { Fairly high sensitivity for precan- } \\
\text { cerous lesions } \\
\text { Longer intervals of testing }\end{array}$ & $\begin{array}{l}\text { More expensive than FIT } \\
\text { Lower specificity than FIT }\end{array}$ \\
\hline $\begin{array}{l}\text { CT colonogra- } \\
\text { phy }\end{array}$ & Tier 2 & Every 5 years & $\begin{array}{l}\text { CRC: sensitivity } 96.1 \% \\
\text { Adenomas } \geq 6 \mathrm{~mm} \text { : sensitivity: } \\
73 \text { to } 98 \% \\
\text { specificity: } 89 \text { to } 91 \% \\
\text { [32] }\end{array}$ & $\begin{array}{l}\text { High sensitivity for CRC and } \\
\text { advanced adenomas }\end{array}$ & $\begin{array}{l}\text { Tedious bowel preparation } \\
\text { Radiation exposure } \\
\text { High cost }\end{array}$ \\
\hline $\begin{array}{l}\text { Flexible sigmoi- } \\
\text { doscopy }\end{array}$ & Tier 2 & $\begin{array}{l}\text { Every } \\
5-10 \text { years }\end{array}$ & Same as colonoscopy & $\begin{array}{l}\text { Prevention by treating premalig- } \\
\text { nant lesions } \\
\text { High sensitivity for CRC and } \\
\text { precancerous lesions } \\
\text { Long screening intervals if } \\
\text { negative }\end{array}$ & $\begin{array}{l}\text { Tedious bowel preparation } \\
\text { High quality standards needed/ } \\
\text { operator dependent } \\
\text { Low but possible risk of adverse } \\
\text { events (bleeding, perforation, } \\
\text { aspiration, splenic injury) } \\
\text { Inability of detecting proximal } \\
\text { CRC }\end{array}$ \\
\hline
\end{tabular}

improve noninvasive CRC screening; however, further development and research is needed.

\section{Conclusion}

The positive impact of colorectal cancer (CRC) screening programs on CRC mortality have been well studied and a variety of different screening algorithms have been established worldwide. Still participation rates are fairly low and the potential benefit could be multiplied by increasing participation rates. Offering multiple screening tests may increase patient acceptance; however, due to the low sensitivity of noninvasive stool tests for precancerous lesions the only effective preventive procedure for CRC other than lifestyle modification remains colonoscopy.

Funding Open access funding provided by University of Innsbruck and Medical University of Innsbruck.

Conflict of interest M. Niederreiter, L. Niederreiter, A. Schmiderer, H. Tilg and A. Djanani declare that they have no competing interests.

Open Access This article is distributed under the terms of the Creative Commons Attribution 4.0 International License (http://creativecommons.org/licenses/by/4.0/), which permits unrestricted use, distribution, and reproduction in any medium, provided you give appropriate credit to the original author(s) and the source, provide a link to the Creative Commons license, and indicate if changes were made.

\section{References}

1. Siegel RL, Miller KD, Jemal A. Cancer statistics, 2019. Ca Cancer JClin. 2019;69(1):7-34.

2. Brenner H, Hoffmeister M, Stegmaier C, Brenner G, Altenhofen L, Haug U. Risk of progression of advanced adenomas to colorectal cancer by age and sex: estimates based on 840149 screening colonoscopies. Gut. 2007;56(11):1585-9.

3. Kahi CJ, Imperiale TF, Juliar BE, Rex DK. Effect of screening Colonoscopy on Colorectal cancer incidence and mortality. Clin Gastroenterol Hepatol. 2009;7(7):770-5.

4. Suchanek S, Ngo O, Grega T, Majek OMZ. Colorectal cancer incidence and mortality reduction in the Czech Republic. United European Gastroenterol J. 2018;6(Supplement 1):7-12.

5. Doubeni CA, Corley DA, Quinn VP, Jensen CD, Zauber AG, Goodman M, et al. Effectiveness of screening colonoscopy in reducing the risk of death from right and left colon cancer: a large community-based study. Gut. 2018;67(2):291-8.

6. Lansdorp-Vogelaar I, Van Ballegooijen M, Zauber AG, Habbema JDF, Kuipers EJ. Effect of rising chemotherapy costs on the cost savings of colorectal cancer screening. J Natl Cancer Inst. 2009;101(20):1412-22.

7. Botteri E, Iodice S, Bagnardi V, Raimondi S, Lowenfels AB, Maisonneuve P. Smoking and Colorectal cancer. JAMA. 2008;300(23):2765.

8. Fedirko V, Tramacere I, Bagnardi V, Rota M, Scotti L, Islami F, et al. Alcohol drinking and colorectal cancer risk: an overall and dose-responsemeta-analysis of published studies. Ann Oncol. 2011;22(9):1958-72.

9. Karahalios A, English DR, Simpson JA. Weight change and risk of colorectal cancer: a systematic review and metaanalysis. Am JEpidemiol. 2015;181(11):832-45. 
10. Bouvard V, Loomis D, Guyton KZ, Grosse Y, El Ghissassi F, Benbrahim-Tallaa L, et al. Carcinogenicity of consumption of red and processed meat. Lancet Oncol. 2015;16(December):1599-600.

11. Kim Y, Mason J. Nutrition Chemoprevention of Gatrointesinal cancers: a critical review. NutrRev. 1996;54(9):259-79.

12. Michels KB, Giovannucci EE, Joshipura KJ, Rosner BA, Stampfer MJ, Fuchs CS, et al. Prospective study of fruit and vegetable consumption and incidence of colon and rectal cancers. J Natl Cancer Inst. 2001;93(11):879.

13. Pan P, Yu J, Wang L-S. Diet and colon. Curr Opin Gastroenterol. 2019;35(2):101-6.

14. Boyle T, Keegel T, Bull F, Heyworth J, Fritschi L. Physical activity and risks of proximal and distal colon cancers: a systematic review and meta-analysis. J Natl Cancer Inst. 2012;104(20):1548-61.

15. Force T, Statement R. Annals of internal medicine clinical guidelines routine aspirin or Nonsteroidal anti-inflammatory drugs for the primary prevention of Colorectal cancer : U . S . Preventive services task force recommendation statement OF.Ann Intern Med. 2007;146(5):361-4.

16. Hewitson P, Pp G, Irwig L, Towler B, Watson E, Hewitson P, et al. Screening for colorectal cancer using the faecal occult blood test, Hemoccult (Review). Cochrane Libr. 2011;2:2-4.

17. Allison JE. Hemoccult screening in detecting Colorectal neoplasm: sensitivity, specificity, and predictive value. Ann Intern Med. 1990;112(5):328.

18. Zhu MM,XuXT, NieF, TongJL, XiaoSD, RanZH. Comparison of immunochemical and guaiac-based fecal occult blood test in screening and surveillance for advanced colorectal neoplasms: a meta-analysis. J Dig Dis. 2010;11(3):148-60.

19. Zorzi M, Fedeli U, Schievano E, Bovo E, Guzzinati S, Baracco S, et al. Impact on colorectal cancer mortality of screening programmes based on the faecal immunochemical test. Gut. 2015;64(5):784-90. https://doi.org/10. 1136/gutjnl-2014-307508

20. Hundt S, Haug U, Brenner H. Article annals of internal medicine comparative evaluation of Immunochemical fecal occult blood tests. Ann Intern Med. 2009;150:162-9.

21. Lanas A, Carrera P, Navarro M, Ferrandez AMC. Increasing the cut-off values of FIT in population based Colorectal cancer screening improves false positive rates and health resource. United European Gastroenterol J. 2018;6(Supplement 1):2018.

22. Quintero E, Castells A, Bujanda L, Cubiella J, Salas D, Lanas Á, et al. Colonoscopy versus fecal immunochemical testing in colorectal-cancer screening. $\mathrm{N}$ Engl J Med. 2012;366(8):697-706.

23. Imperiale TF, Ransohoff DF, Itzkowitz SH, Levin TR, Lavin P, Lidgard GP, et al. Multitarget stool DNA testing for Colorectal-cancer screening. N Engl J Med. 2014;370(14):1287-97. https://doi.org/10.1056/NEJMoa1311194.
24. Gupta N, Kupfer SS, Davis AM. Colorectal cancer screening. JAMA. 2019;160(3):171-81. https://doi.org/10.7326/M131484.

25. Zauber AG, Winawer SJ, O’Brien MJ, et al. Colonoscopic Polypectomy and long-term prevention of Colorectal-cancer deaths. NEngl J Med. 2012;366(8):687-96.

26. Schoen RE, Pinsky PF, Weissfeld JL, Yokochi LA, Church T, Laiyemo AO, et al. Colorectal-cancer incidence and mortality with screening flexible Sigmoidoscopy. N Engl J Med. 2012;366(25):2345-57.

27. Miller EA, Pinsky PF, Schoen RE, Prorok PC, Church TR. Effect of flexible sigmoidoscopy screening on colorectal cancer incidence and mortality: long-term follow-up of the randomised US PLCO cancer screening trial. Lancet Gastroenterol Hepatol. 2019;4(2):101-10. https://doi.org/ 10.1016/S2468-1253(18)30358-3.

28. El-Maraghi RH, Kielar AZ. CT Colonography versus optical Colonoscopy for screening asymptomatic patients for Colorectal cancer. Acad Radiol. 2009;16(5):564-71.

29. De Haan MC, Van Gelder RE, Graser A, Bipat S, Stoker J. Diagnostic value of CT-colonography as compared to colonoscopy in an asymptomatic screening population: a meta-analysis. Eur Radiol. 2011;21(8):1747-63.

30. Normanno N, Cervantes A, Ciardiello F, De Luca A, Pinto C. The liquid biopsy in the management of colorectal cancer patients: current applications and future scenarios. Cancer TreatRev. 2018;70(May):1-8.

31. Imperiale TF, Kahi CJ, Rex DK. Lowering the starting Age for Colorectal cancer screening to 45 years: who Will come ... and should they? Clin Gastroenterol Hepatol. 2018;16(10):1541-4.

32. Wolf AMD, Fontham ETH, Church TR, Flowers CR, GuerraCE,LaMonteSJ, etal. Colorectal cancerscreeningfor average-risk adults: 2018 guideline update from the American Cancer Society. Ca Cancer J Clin. 2018;68(4):250-81.

33. Knudsen AB, Zauber AG, Rutter CM, Naber SK, DoriaRose VP, Pabiniak C, et al. Estimation of Benefits, Burden, and Harms of Colorectal Cancer Screening Strategies. JAMA. 2016;315(23):2595. Jun21.

Publisher's Note Springer Nature remains neutral with regard to jurisdictional claims in published maps and institutional affiliations.

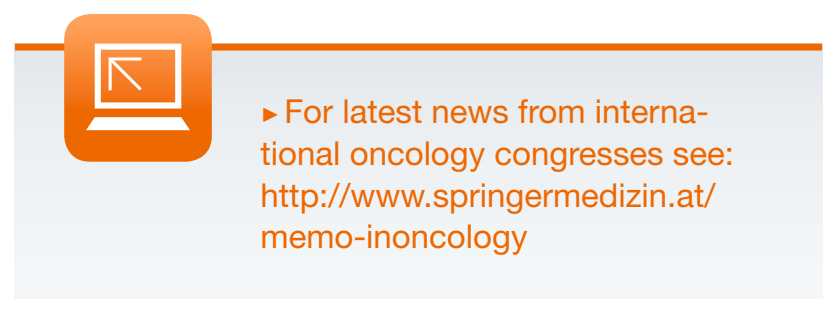

